\title{
Scanning Electron Microscopic Study of the Developing Vallate Papillae in the Korean Native Goat (Capra hircus)
}

\author{
Gyuhyen Cho, Munki Kim, Sijoon Lee, Chongsup Kim and ${ }^{\dagger}$ Chungkil Won \\ Institute of Animal Medicine \& Department of Veterinary Medicine, Gyeongsang National University, \\ Jinju 62882, Korea
}

\begin{abstract}
The purpose of the present study was to investigate the morphological characteristics of the developing vallate papillae (VP) of Korean native goats using scanning electron microscopy. In prenatal development of the VP, primordia of the VP were observed and the moat was shallowly spread in 60-day-old fetuses. The moat of the vallate papillae was shallowly spread and still undifferentiated in 90-day-old fetuses. The trench wall of the moat of the VP was well developed in 120-dayold fetuses. In neonates, the moat of the VP was more widely and deeply engraved and VP were developed as completely as those of adults. In postnatal development, VP were observed to have continually increased in size with slight morphological changes until 90-days after birth. Taste pores of the VP were shaped like flower leaves in 120-days after birth. The microridges and microplicaes were well developed on the epithelial surface of the VP in goats ranging from 120-day-old fetuses to 120-day-old postnatal animals. These results suppose that the sensing ability for gestation of VP was already well developed by the time of its birth and VP were differentiated into a variety of different shape and size during development.

Key words : Development, Korean native goat, Morphogenesis, Tongue, Vallate papillae
\end{abstract}

\section{INTRODUCTION}

The dorsal surface of tongue contains numerous macroscopic papillae. These papillae differ somewhat in shape, are named according to their morphologic characteristics, and serve either a mechanical or a gustatory function (Davies et al., 1979; Boshell et al., 1982; Chamorro et al., 1986; Holland et al., 1989; Kumar and Bate, 2004). Me-chanical papillae were able to divide it into filiform, conical and lentiform papillae, and gustatory papillae were divided into fungiform, vallate and foliate papillae (Witt and Reutter, 1997). Goats have three different types of mechanical papillae and two different types of gustatory papillae according to their shape (Lee et al., 1996; Kumar et al., 1998).

Scanning electron microscopic studies of the tongue papillae in various animals have been reported for rodents (Iwasaki et al., 1996; Iwasaki et al., 1997), carnivore (Boshell et al., 1982; Holland et al., 1989; Ojima, 2001), ruminants (Davies et al., 1979; Emura et al., 2000; Eerdunchaolu et al., 2001), pigs (Kumar and Bate, 2004), horses (Chamorro et al., 1986; Pfeiffer et al., 2000), and various wild animals (Krause and Cutts., 1982; Furubayashi et al., 1989; Emura et al., 2004). A few studies have been performed with goats, examining their filiform, fungiform, conical, vallate,

\footnotetext{
Manuscript received October 16, 2016, Received in revised form November 15, 2016, Accepted December 8, 2016

$\dagger$ Corresponding Author : Chungkil Won, Institute of Animal Medicine \& Department of Veterinary Medicine, Gyeongsang National University, Jinju, 62882, Korea. Tel. : +82-55-772-2351, Fax : +82-55-772-2308, E-mail : wonck@gnu.ac.kr

This is an Open Access article distributed under the terms of the Creative Commons Attribution Non-Commercial License (http:// creativecommons.org/licenses/by-nc/3.0) which permits unrestricted non-commercial use, distribution, and reproduction in any medium, provided the original work is properly cited.
} 
and lentiform papillae (Lee et al., 1996; Kumar et al., 1998). However, much less has been written about the morphological characteristics of the developing tongue in goats (Kim et al., 2012). Therefore, to understand the progress of developing vallate papillae (VP) in goats, we investigated the features of the VP on the dorsal surface of the tongue during development as shown by scanning electron microscopy.

\section{MATERIALS AND METHODS}

\section{Experimental animals}

The tongues from three fetuses, four neonates and six juveniles of Korean native goat were used in each group. To investigate the morphological characteristics of the tongue during prenatal development, the tongues examined in this study were removed from 60, 90, 120, 150-day-old fetuses (neonates) originated from Korean native goats aged 2 to 4 years old with a body weight ranging from 23 to $33 \mathrm{~kg}$ by caesarean section and performed under general anesthesia using xylazine hydrochloride $(10 \mathrm{mg} / \mathrm{kg}$, i.v.; Bayer Korea Ltd.). The VP of the tongues were examined for morphological features. We also removed the tongues from goats at six different postnatal stages: on days 30, 60, 90, 120,150, and 180, respectively. All animal experiments were performed according to the protocol set out in the guidelines of the Ethics Committee for Animal Experiments at Gyeongsang National University (Approval No. GNULA-10).

\section{SEM examinations of the developing VP}

Tissues for scanning electron microscopy (SEM) studies were fixed using $2.5 \%$ glutaraldehyde $4 \mathrm{~h}$ at room temperature. Areas appropriate for inspection were dissected and osmicated in $1.0 \%$ osmium tetroxide at $4^{\circ} \mathrm{C}$ for $2 \mathrm{~h}$. After washing with PBS three times, the tissues were dehydrated using a graded series of ethanol solutions. The specimens were prepared for critical drying point, and then placed on spinner stubs, and coated with gold to a depth of $100 \mu \mathrm{m}$ in a SEM coating unit. The specimens were observed under a SEM (SEM-AL 300, Philips) operated at $15 \mathrm{KV}$.

\section{SEM measurements of the length of the VP}

The measurement of the VP from three to five different regions was performed by using a scanning electron microscope to measure the minimum and maximum diameters of the papillae of neonates to 180-day-old goats. We analyzed the statistical significance of differences in each group by using a two-tailed Student's $t$-test (Prism; Graph Pad Software).

\section{RESULTS}

\section{Morphological characteristics of developing VP}

The VP of the goats were located on both sides of the midline around the tongue root during development. In prenatal development of the VP, round and low primordia of the VP was seen in 60-day-old fetuses (Fig. 1A). The moat of the VP was shallowly spread and still undifferentiated in 90-day-old fetuses (Fig. 1B). In 120-day-old fetuses, there was a deeply furrowed in the moat entirely surrounding the primordia of the VP (Fig. 1C); and the microridges and microplicae were well developed on the surface of the VP (Fig. 3A). In neonates, the VP were developed as complete as those of adults (Fig. 1D); and the developing taste pore was also observed on the epithelial surface of VP (Fig. 3B).

In postnatal development of the VP, the papillae were increased in size with slight morphological changes in postnatal day-30 (Fig. 2A). In postnatal day-60, twin VP were found to be surrounded by one primary papillary groove; and two VP that shared a moat was found (Fig. 2B). The microplicae and microridges on the epithelial surface of VP were thick and windingly round shape in 

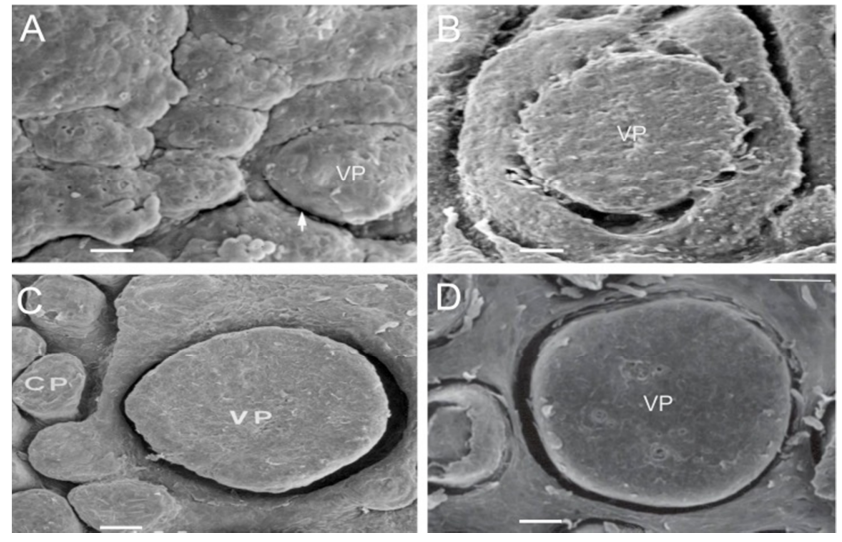

Fig. 1. Scanning electron micrographs showing the prenatal vallate papillae of Korean native goats. (A) Prenatal day-60, (B) Prenatal day-90, (C) Prenatal day-120, (D) Prenatal day-150 (neonate). VP: vallate papilla, CP: conical papilla, Scale bar $=100 \mu \mathrm{m}$.
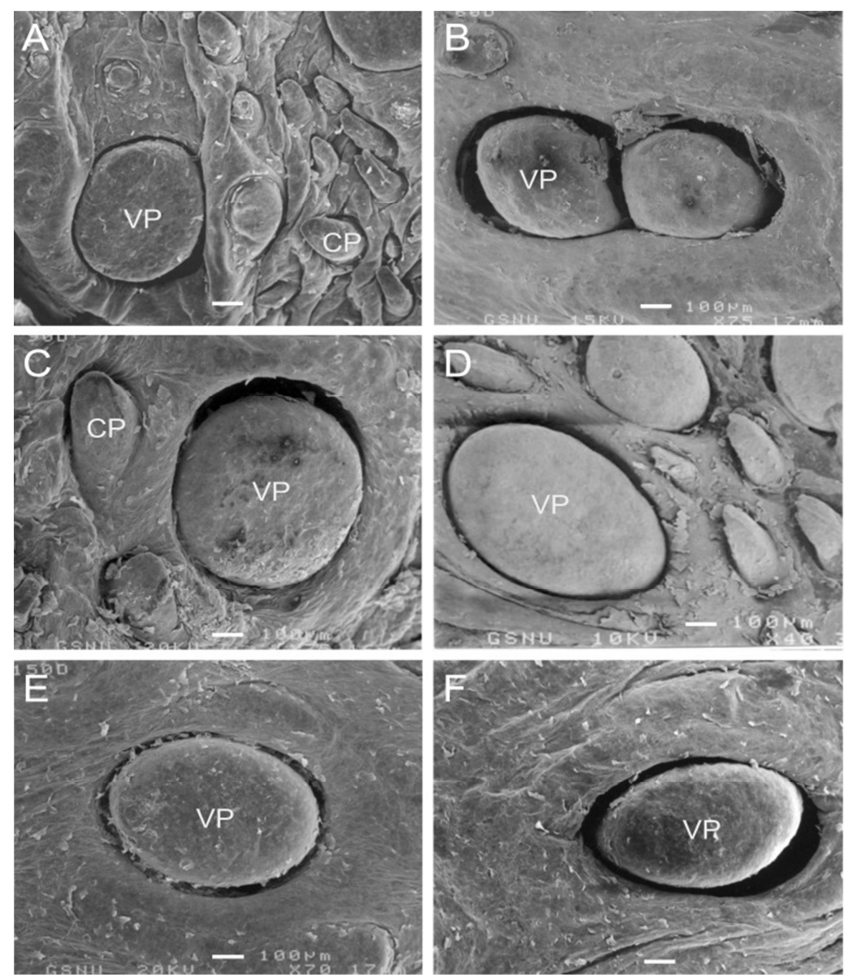

Fig. 2. Scanning electron micrographs showing the post natal vallate papillae of Korean native goats. (A) Postnatal day-30, (B) A pair of vallate papillae was seen at postnatal day-60. (C) Postnatal day-90, (D) Postnatal day-120, (E) Postnatal day-150, (F) Postnatal day-180. VP: vallate papilla, CP: conical papilla, Scale bar $=100 \mu \mathrm{m}$.
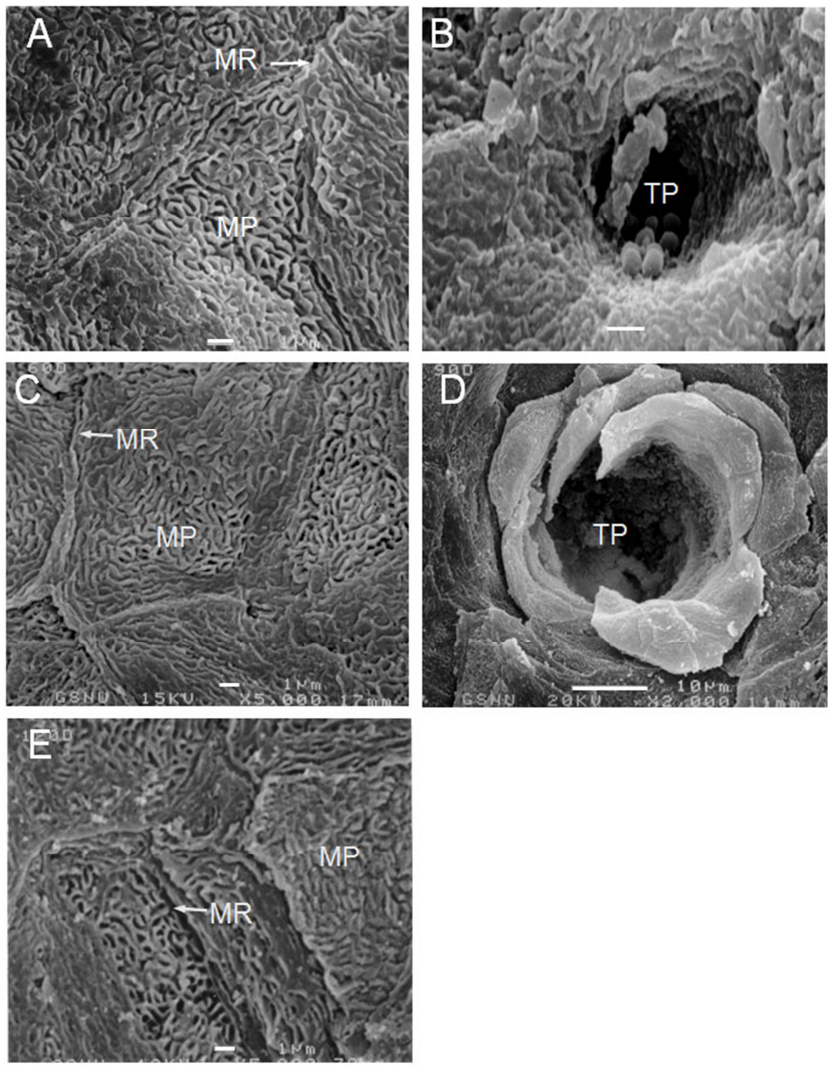

Fig. 3. Higher magnification view of the epithelial surface of the developing vallate papillae. (A) Prenatal day-120, (B) Neonate, (C) Postnatal day-60, (D) Postnatal day-90, (E) Postnatal day-120. MP: microplica, MR: microridge, TP: taste pore. Scale bars in A, B, $\mathrm{C}, \mathrm{E}=1 \mu \mathrm{m}, \mathrm{D}: 10 \mu \mathrm{m}$.

postnatal day-60 (Fig. 3C).

In postnatal day-90, some of the VP moats had either a wide and deep portion or a low and narrow portion (Fig. $2 \mathrm{C})$. The taste pores of VP in postnatal day-90 were shaped like flower leaves with microplicae and microridges (Fig. $3 \mathrm{D})$.

In postnatal day-120 and -150 , the VP were somewhat increased in size without much difference in shape (Figs. 2D, E); and the microplicae and microridges were very well developed on the epithelial surface in postnatal day120 (Fig. 3E). In postnatal day-180, the moats of VP were more widely and deeply engraved than those of 150-dayold goats (Fig. 2F). 


\section{Lengths of the developing VP}

The sizes of the goat's VP from neonates age to 180days-old were shown in Fig. 4. The minimum and maximum diameters of newborn papillae were $351.0 \pm 94.0$ and $468.0 \pm 53.0 \mu \mathrm{m}$ respectively. Comparatively, the papillae diameters of 30-day-old goats were $429.0 \pm 57.0$ and 516.0 $\pm 63.0 \mu \mathrm{m}$. Those of 60 -day-old goats were $551.0 \pm 79.0$ and $612.0 \pm 73.0 \mu \mathrm{m}$. Those of 90-day-old goats were $659.0 \pm$ 68.0 and $716.0 \pm 75.0 \mu \mathrm{m}$. Those of 120-day-old goats were $611.0 \pm 75.0$ and $756.0 \pm 91.0 \mu \mathrm{m}$. Those of 150-day-old goats were $613.0 \pm 78.0$ and $731.0 \pm 97.0 \mu \mathrm{m}$. Lastly the papillae diameters of 180-day-old goats were $654.0 \pm 84.0$ and $768.0 \pm 96.0 \mu \mathrm{m}$, respectively. However, no statistically significant differences were found between each age during the next 30 days of life.

\section{DISCUSSION}

There are many reports based on scanning electron microscopy of the three-dimensional structures of the lingual papillae in mammals (Davies et al., 1979; Boshell et al., 1982;

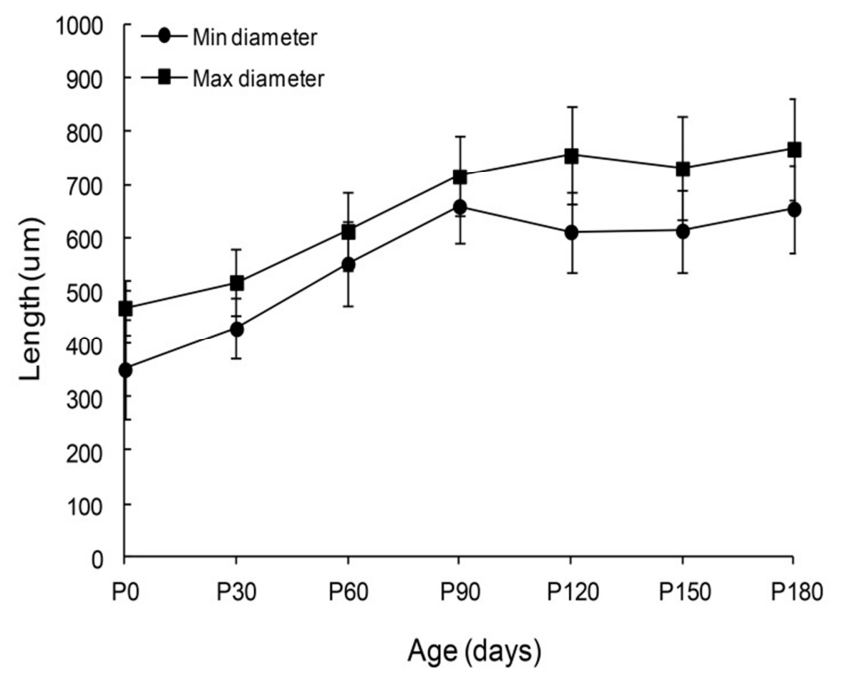

Fig. 4. Scanning electron microscopy measurements of the length of vallate papillae. Each of the minimum and maximum diameters was measured in Korean native goats ranging from neonates ( $\mathrm{P} 0)$ to 180-day-old goats (P180).
Chamorro et al., 1986; Holland et al., 1989; Kumar and Bate., 1998). Kumar et al. (1998) have studied the tongue for filiform, fungiform, conical, vallate and lentiform papillae on the dorsal surface of the goat tongue. Lee et al. (1996) also performed scanning electron microscopic studies of the tongue. However, no comparative studies on changes in the three-dimensional structure of the VP during the development of goats using SEM have been reported.

Concerning the development of lingual papillae, gustatory papillae grow faster than mechanical papillae in humans (Chunhabundit et al., 1992). In mice and rats, the primordia of filiform papillae are formed after the appearance of the rudiments of fungiform and VP (Iwasaki et al., 1996; Iwasaki et al., 1997). On the other hand, the primordia of conical papillae remain in a less-developed form in 90-day-old goat fetuses (Kim et al., 2012). In this study, however, the primordia of VP were found to be better developed than those of the conical papillae in 90-day-old goat fetuses. Therefore, our finding that gustatory papillae were developed prior than mechanical papillae followed the same trend that has been shown to be the case in rodents and humans.

During development, the conical papillae of the mechanical papillae had been found to have an obliquely-sectioned cylindrical shape with an empty inside in 50 day-old goats; and they were observed to have a completely compacted shape on inner surface in 60 day-old goats (Kim et al., 2012) In this study, however, the VP of the gus-tatory papillae were had a round or an oval shape during development; and their papillae in neonates appear to be shaped similar to those of adults. Therefore, these results confirmed that the mechanism governing morphogenesis and the development of gustatory papillae might be differ-rent from that of mechanical papillae.

The morphology of the VP in the newborn mouse had been found to have central papillae and flanking papillae, which formed a horseshoe-like structure around the central papillae (Iwasaki et al., 1996). The tongue of the tree shrew had been found to have pin-cone-like papillae having small 
and many pins (Chunhabundit et al., 1992). Opossum tongue had been found to have a typical vallate-like shape surrounded by a deep moat with small secondary papillae observed on the tips of the VP (Krause and Cutts., 1982). However, a flattened-oval-like shape and secondary papillae were not observed in ruminants (Lee et al., 1996; El Sharaby et al., 2012), they were not observed in the present study of developing goats. On the contrary, complex VP were sometimes spotted on the tongues of adult Korean native goats (Lee et al., 1996). Similarly, two fused VP were also observed in this study.

According to the morphology of the epithelial surface, the surface structure of the lingual epithelia of 12-day-old rat fetuses and those of 15-day-old mouse fetuses had been found to be very similar (Iwasaki et al., 1996; Iwasaki et al., 1997). In this study, the microridges in 120-day-old fetuses were compactly sticking up on the surface of VP. Likewise, well-developed microplicae on the epithelial surface of lingual papillae having similar surface structures were observed in 120-day-old goats. Therefore, the surface structures of the lingual epithelia in Korean native goats were very similar to those of other species.

Concerning the size of the lingual papillae of Korean native goats, Lee et al (1996) reported that, for Korean native goats weighing approximately $15 \mathrm{~kg}$, the VP were round or oval in shape and their diameter ranging from 500 to $850 \mu \mathrm{m}$ with the average number of VP being 34.8. In this study, papillae sizes were 351 468 $\mu \mathrm{m}$ in diameter among newborns, 551 612 $\mu \mathrm{m}$ in diameter among 60-dayold goats during the weaning period, and $654 \sim 768 \mu \mathrm{m}$ in the maturation period of 180-day-old goats. Although the size of the VP in adult goats was similar to those of other studies, that size gradually increased until the 90-day-old goat during development. However, conical papillae belonging to mechanical papillae were still increased in size even after 120 days following birth (Kim et al., 2012). Taken together, these findings indicate that the VP of goats manifest in a variety of shape and size during both prenatal and postnatal development.

\section{REFERENCES}

Boshell JL, Wilborn WH, Singh BB (1982) Filiform papillae of cat tongue. Acta Anat 114:97-105

Chamorro CA, de-Paz P, Sandoval J, Fernandez JG (1986) Comparative scanning electron-microscopic study of the lingual papillae in two species of domestic mammals (Equus caballus and Bos taurus). 1. Gustatory Papillae. Acta Anat (Basel) 125:83-87.

Chunhabundit P, Thongpila S, Somana R (1992) SEM study on the dorsal lingual surface of the common tree shrew, Tupaia glis. Acta Anat (Basel) 143:253-257.

Davies RO, Kare MR, Cagan RH (1979) Distribution of taste buds on fungiform and circumvallate papillae of bovine tongue. Anat Rec 195:443-446.

Eerdunchaolu, Takehana K, Yamamoto E, Kobayashi A, Cao G, Baiyin, Ueda H, Tangkawattana P (2001) Characteristics of dorsal lingual papillae of the Bacterian Camel (Camelus bactrinus). Anat Histol Embryol 30: 147-151.

El Sharaby AA, Alsafy MA, El-Gendy SA, Wakisaka S (2012) Morphological characteristics of the vallate papillae of the one-humped camel (Camelus dromedarius). Anat Histol Embryol 41:402-409.

Emura S, Hayakawa D, Chen H, Shoumura S (2004) Morphology of the lingual papillae in the tiger. Okajimas Folia Anat Jpn 81:39-43.

Emura S, Tamada A, Hayakawa D, Chen H, Shoumura S (2000) Morphology of the dorsal lingual papillae in the barbary sheep (Ammotragus lervia). Okajim Folia Anat Jpn 77:39-45.

Furubayashi R, Sato E, Ishibashi T (1989) Histological pattern of the tongue in the Japanese weasels. Mastela itatsi, with special reference to the morphology and 
distribution of papillae, taste buds and lingual gland.

Acta Anat 64:210-214.

Kim GS, Cho GH, Won CK (2012) Scanning electronic microscopy study of the developing fungiform papillae of Korean native goats (Capra hircus). J Biomed Res 13:223-227.

Holland VF, Zampighi GA, Simon SA (1989) Morphology of fungiform papillae in canine lingual epithelium: location of intercellular junctions in the epithelium. $\mathrm{J}$ Comp Neurol 279:13-27.

Iwasaki S, Yoshizawa H, Kawahara I (1996) Study by scanning electron microscopy of the morphogenesis of three types of lingual papilla in the mouse. Acta Anat 157:41-52.

Iwasaki S, Yoshizawa H, Kawahara I (1997) Study by scanning electron microscopy of the morphogenesis of three types of lingual papillae in the rat. Anat Rec 247: 528-541.

Kim GS, Cho GH, Won CK (2012) Scanning electronic microscopic observation on the development of conical papillae in Korean native goats (Capra hircus). J Biomed Res 13(4):326-330.

Krause WJ and Cutts JH (1982) Morphological observa- tions on papillae of the opossum tongue. Acta Anat 113:159-168.

Kumar S, Bate LA (2004) Scanning electron microscopy of the tongue papillae in the pig (Sus scrofa). Microsc Res Tech 63:253-258.

Kumar P, Kumar S, Singh Y (1998) Tongue papillae in goat: A scanning electron-microscopic study. Anat Histol Embryol 27:355-357.

Lee HS, Lee IS, Kang TC (1996) Morphological study on the tongue of Korean native goat. Korean J Vet Res $36: 255-264$.

Ojima K (2001) Functional role and angioarchitectural arrangement of the filiform papillae on the mediodorsal surface of the beagle dog tongue. Ann Anat 183: 325-329.

Pfeiffer CJ, Levin M, Lopes MAF (2000) Ultrastructure of the horse tongue: Further observation on the lingual integumentary architecture. Anat Histol Embryol 29: $37-43$.

Witt MI, Reutter K (1997) Scanning electron microscopical studies of developing gustatory papillae in humans. Chem Senses 22:601-612. 